\title{
Assessment of Awareness of Risks to Prevent Uterine Prolapse among Young Married Women in Selected Villages of District Sirmour, Himachal Pradesh
}

Kaur $\mathrm{G}^{1 *}$, Preet $\mathrm{K}^{2}$, Kaushal $\mathrm{N}^{2}$, Kaur $\mathrm{S}^{3}$ and Kaur $\mathrm{N}^{4}$

${ }^{1}$ Lecturer, Baba Ghulam Shah University, India

${ }^{2}$ MPH Scholar, India

${ }^{3}$ Assistant Professor, Department of Public Health, Eternal University, India

${ }^{4}$ Dean Faculty of Health and Allied Sciences, Eternal University, India

\section{Research Article}

Volume 4 Issue 3

Received Date: March 27, 2020

Published Date: May 18, 2020

DOI: $10.23880 /$ nhij-16000221

*Corresponding author: Gurjyot Kaur, College of Nursing Baba Ghulam Shah University, India, Tel: 7986853875; Email: gurjyot40mk@gmail.com

\section{Abstract}

Introduction: Pelvic organ prolapse is one of the common clinical conditions met in day-to-day gynaecological practice, especially amongst parous women. A study was conducted to assess awareness of risk to prevent uterine prolapse among young married women in selected villages of District Sirmour, Himachal Pradesh.

Objectives: To assess the awareness of risk regarding uterine prolapse and To find out association of the awareness of risk findings with selected demographic variables.

Methodology: Quantitative research approach using Descriptive research design was used. Non-probability convenience sampling was opted to get sample of 260 Married women of 19-30 years age group from selected villages of District Sirmour, H.P. Structured interview schedule was used to assess the awareness of risk.

Results: The results showed that about $45 \%$ of women had low level knowledge, $41.5 \%$ had moderate level and $13.5 \%$ remaining had high level awareness regarding risk of uterine prolapse. There was a significant relationship between education, occupation, hours of working, type of work, age at marriage, age at birth of first child, place of delivery, person conducting delivery with awareness of risk regarding uterine prolapse.

Conclusion: With the changing health trends, it must emphasize on primary health care approach focusing on prevention rather than cure. Awareness programmes regarding risk factors to prevent uterine prolapse should be organised at regular intervals. In order to prevent uterine prolapse, proper health care during antenatal, intra-natal and postnatal period should be provided.

Keywords: Uterine Prolapse; Risks; Prevention; Awareness; Married women

\section{Introduction}

The uterus is not in an affixed position in pelvis. Sharmilla [1] discussed that minor variations in position occur with changes in posture with straining and with full bladder or rectum. Pelvic organ prolapse is one of the common clinical conditions met in day-to-day gynaecological practice, especially amongst parous women. 
Uterine prolapse (also called a fallen uterus or uterine descensus) is generally a by-product of aging, injury to vaginal tissues, or both. As per Carlson, et al. [2] it is most common in women who have delivered babies vaginally, particularly if they have had many children or experienced long or difficult labours or deliveries (which increase the chances of permanent damage to the pelvic support structures). In addition to childbirth, excessive abdominal pressure or stress can weaken pelvic support. For this reason, some jobs requiring heavy lifting can predispose women to uterine prolapse.

Lowdermilk, et al. [3] found out that uterine prolapse is a more serious type of displacement. The degrees of prolapse vary from mild to complete. Uterine displacement and prolapse can be caused by congenital or acquired weakness of the pelvic support structures (often referred to as pelvic relaxation). The contributing causes of uterine prolapse are pelvic trauma, stress, strain and the aging process.

The female genital organs are maintained in their normal anatomical position by a number of fascial condensations (endopelvic fascia) referred to as ligaments, especially the transverse cervical (cardinal) and uterosacral ligaments. Ojiyi, et al. [4] mentioned that weakness in any of these supportive structures leads to uterine descent, particularly around the period of menopause when estrogen withdrawal causes a second insult to the integrity of the pelvic supports already weakened by repeated vaginal deliveries. Hence, childbirth and aging constitute the most important associated factors of female genital prolapse.

According to Hoffmann, et al. [5] pelvic organ prolapse is a health concern affecting millions of women worldwide. In the United States, it is the third most common indication for hysterectomy. The estimation of disease prevalence has been hampered by lack of a consistent definition of pelvic organ prolapse. If the validated Pelvic Organ Prolapse Quantification (POP-Q) examination alone is used to describe pelvic organ support, $30 \%$ to $65 \%$ of women presenting for routine gynaecologic case have stage 2 prolapse.

Pelvic organ prolapse has a high overall prevalence of $46 \%$ in the well-defined population of rural Gambian women. Scherf, et al. [6] surveyed that $14 \%$ had a serious degree of prolapse warranting surgical intervention. The survey's high participation rate among the eligible women resident in the study area makes this an accurate assessment of the largest population of women studied to date. It was found that high parity is the single most important risk factor for prolapse in rich and poor women in both more and less developed countries.
The study revealed that the higher burden of uterus prolapse is found in those with poor economic background, those aged above 30 years and with more than two deliveries conducted at home. Binjwala, et al. [7] study concluded that $53 \%$ of the women in this study had never heard about uterine prolapse. The age of respondents, occupation, age at first birth, place of delivery, work load during the peurperium period, time to resume work after delivery, number of delivery and person providing assistance during delivery were the key associated factors. In most cases, ring pessary was applied and significant improvement in their health was reported. However, 69\% had not used any treatment mainly due to poor socioeconomic status. Therefore, it was recommended that uterine prolapse-related health promotion programs should target women in all caste/ethnic groups, age groups, and education status nationwide, including both urban and rural communities.

\section{Statement of the Problem}

A descriptive study to assess awareness of risk to prevent uterine prolapse among young married women in selected villages of District Sirmour, Himachal Pradesh.

\section{Aim}

To assess awareness of risk to prevent uterine prolapse among young married women.

\section{Objectives}

- To assess the awareness of risk regarding uterine prolapse.

- To find out association of the awareness of risk findings with selected demographic variables.

\section{Operational Definitions}

Awareness: It means the factual information that a person knows and is measured by correct responses obtained from women regarding risk of uterine prolapse.

Measures: A plan or action adopted by a women regarding prevention of uterine prolapse.

Uterine prolapse: It means sliding down of the uterus from the vagina in the women having uterine prolapse.

Married women: It refers to those women aged between 19- 30 years residing at selected villages of District Sirmour, Himachal Pradesh. 


\section{Research Methodology}

\section{Schematic Diagram of Research Methodology (Figure 1)}

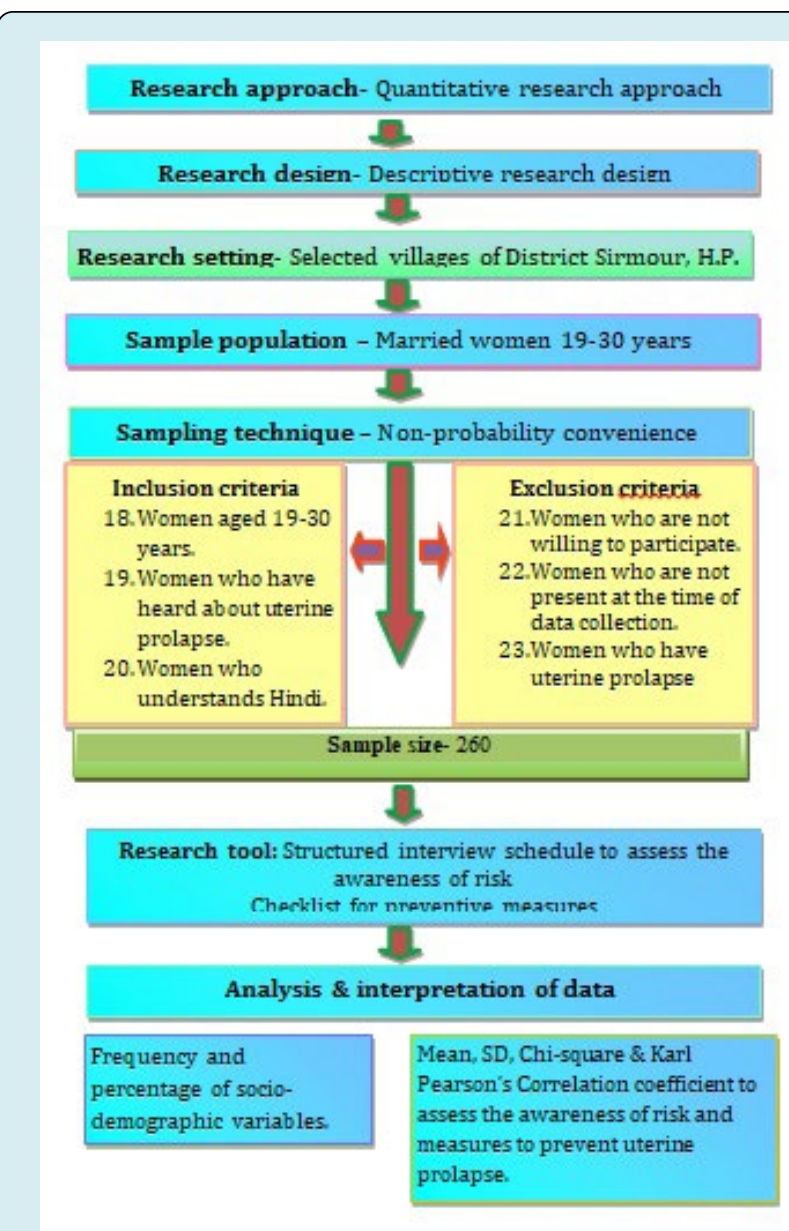

Figure 1: Schematic diagram of research methodology.

\section{Research Approach}

The quantitative research approach was used in this research study. Questionnaires with set questions and answers were given away to the respondents who responded from the options asked. This research approach focused on how people feel and what they think.

\section{Research Design}

Non-experimental descriptive design was used as a research design. The purpose of descriptive studies is to observe and describe aspects of a situation as it naturally occurs. A descriptive design provides an accurate portrayal or account of characteristics of a particular individual, situation or group. In this study, data was collected on the awareness of risk to prevent uterine prolapse.

\section{Variables}

Demographic variables: The demographic variables in this study were age of the respondents, education, occupation, hours of working, type of work, income, marital status, age at marriage, parity, age at birth of first child, place of delivery, person conducting delivery and any complications during delivery.

Research variables: The research variable in this study was risk to prevent uterine prolapse.

\section{Research Setting}

The research setting for the study was the selected villages-Dimber, Nanu, Lana Balta, Kheri, Macher, Banog and Rajgarh of District Sirmour, H.P.

\section{Population}

The population comprised of married women aged 1930 years from selected villages of District Sirmour, H.P.

\section{Criteria for Sample Selection}

\section{Inclusion criteria}

- Women aged 19-30 years.

- Women who have heard about uterine prolapse.

- Women who understands Hindi.

\section{Exclusion criteria}

- Women who are not willing to participate.

- Women who are not present at the time of data collection.

- Women who have uterine prolapse.

\section{Sampling Technique}

Non- Probability Convenience sampling technique has been used to select the sample for the study as they were easy to my reach and are accessible.

\section{Sample Size}

260 samples had been selected in my study according to the prevalence rate. The sample size was calculated using the formula:

$$
\mathrm{n}=\frac{\mathrm{Z} 2(\mathrm{p}(1-\mathrm{p}))}{\mathrm{d} 2}
$$

Where,

$\mathrm{n}$ is the size of sample;

$\mathrm{Z}$ is the $\mathrm{z}$-statistics for the desired level of confidence; $p$ is the estimate of expected proportion with the variable of interest in the population;

$\mathrm{d}$ is the half width of the desired interval (precision) 
$(1.96)^{2} \times 0.20 \times 0.8 /(0.05)^{2}$

$3.84 \times 0.20 \times 0.8 / 0.0025=245$

Calculated sample size $=245$

Study sample $=260$

The sample size was increased to prevent bias.

\section{Development and Description of Tool}

The structured interview schedule was developed by the investigator to assess the awareness of risk regarding uterine prolapse.

Preparation of the tool was done by

- Review of Literature.

- Discussion with guide and nursing experts.

The tool consisted of the following sections:

Section A: Demographic variables such as age of the respondents, education, occupation, hours of working, type of work, income, marital status, age at marriage, parity, age at birth of first child, place of delivery, person conducting delivery and any complications during delivery.

Section B: Structured interview schedule to assess awareness of risk regarding uterine prolapse. This section consisted of 12 questions. A score of 1 was given for correct response (yes) and 0 for incorrect response (no).

The scores were categorised using Modified Blooms cut off point as:

- High level- 80-100\%

- Moderate level- 50-79\%

- Low level- $<50 \%$

\section{Content Validity}

Validity of tool was done by 5 external experts from nursing and medicine to check the content validity. Internal validation was done by five experts: 5 Assistant Professors of Akal College of Nursing, Baru Sahib. External validation was done by five experts: 4 Assistant Professor (SNGNC Shimla) and 1 Professor (Kamla Nehru Hospital, Shimla). Relevant modifications were made as per suggestions of the experts and the changes were incorporated in the tool.

\section{Reliability of the Tool}

The Karl Pearson's correlation coefficient was used to assess the awareness of risk to prevent uterine prolapse. With a correlation coefficient value i.e, $r=0.7$, it was strongly positively correlated and there it was concluded that the tool was reliable. Internal consistency was evaluated by using split half method.

\section{Ethical Consideration}

The permission was obtained from the Principal, Akal College of Nursing Baru Sahib. Permission was taken from the Pradhans of various panchayats prior to collection of data. Informed written consent was obtained from the study participants before the collection of information. The purpose of the study was explained to the subjects in their own language and confidentiality of the information was ensured.

\section{Pilot Study}

Pilot study was conducted to find the feasibility of the tool after obtaining formal permission from the concerned authority. The data was collected from 26 respondents by using structured interview at selected village of District Sirmour- Bagroti in the month of November through nonprobability convenience sampling technique. The samples that are included in Pilot study were not included in the main study. The tool was found reliable with reliability score of 0.70 .

\section{Procedure of Data Collection}

After obtaining permission from the concerned authorities; informed written consent from the selected respondents, the investigator collected the data pertaining to the demographic variables. Data was collected by using close ended questions in the form of structured interview. Interview was carried out to get the information. It took 15 minutes to collect data from each sample. Each day 9 samples were taken.

\section{Plan for Data Analysis}

The data collected was grouped and analysed by descriptive and inferential statistics.

\section{Descriptive Statistics}

- Frequency and percentage distribution of selected demographic variables.

- Frequency and percentage distribution of awareness of risk findings regarding uterine prolapse.

Inferential statistics: The association between selected demographic variables and awareness of risk findings will be analysed by using chi square.

\section{Results \& Discussion}

\section{Data Analysis \& Interpretation}

This chapter deals with the detailed description of the findings obtained from the analysis of observations. The gathered data was first coded and summarised in a master sheet and then analysed by using statistical package for social sciences (SPSS 15). The variables were described in percentages, means, and standard deviation, depending 
on the nature of the variables. After obtaining results from data analysis the discussion was done which is described in terms of results of the current study and comparing it with previous studies.

It deals with the analysis and interpretation of data, collected from 260 respondents regarding awareness of risk and measures to prevent uterine prolapse. The data was organised, analysed and interpreted by using descriptive and inferential statistics. Analysis and interpretation was done based on objectives of the study.

In current study, data analysis is described in the following sections:

Section A: Frequency and percentage distribution of demographic variables of the sample.

Section B: Assessment of awareness of risk findings regarding uterine prolapse among married women.

Section C: Association between awareness of risk findings with selected demographic variables.

\section{Section A: Frequency and percentage distribution of demographic variables of the samples}

This section depicts about the profile of the samples. The socio demographic profile includes age, education, occupation, hours of working, type of work, income, marital status, age at marriage, parity, age at birth of first child, place of delivery, person conducting delivery and any complications during delivery (Figures 2-14).
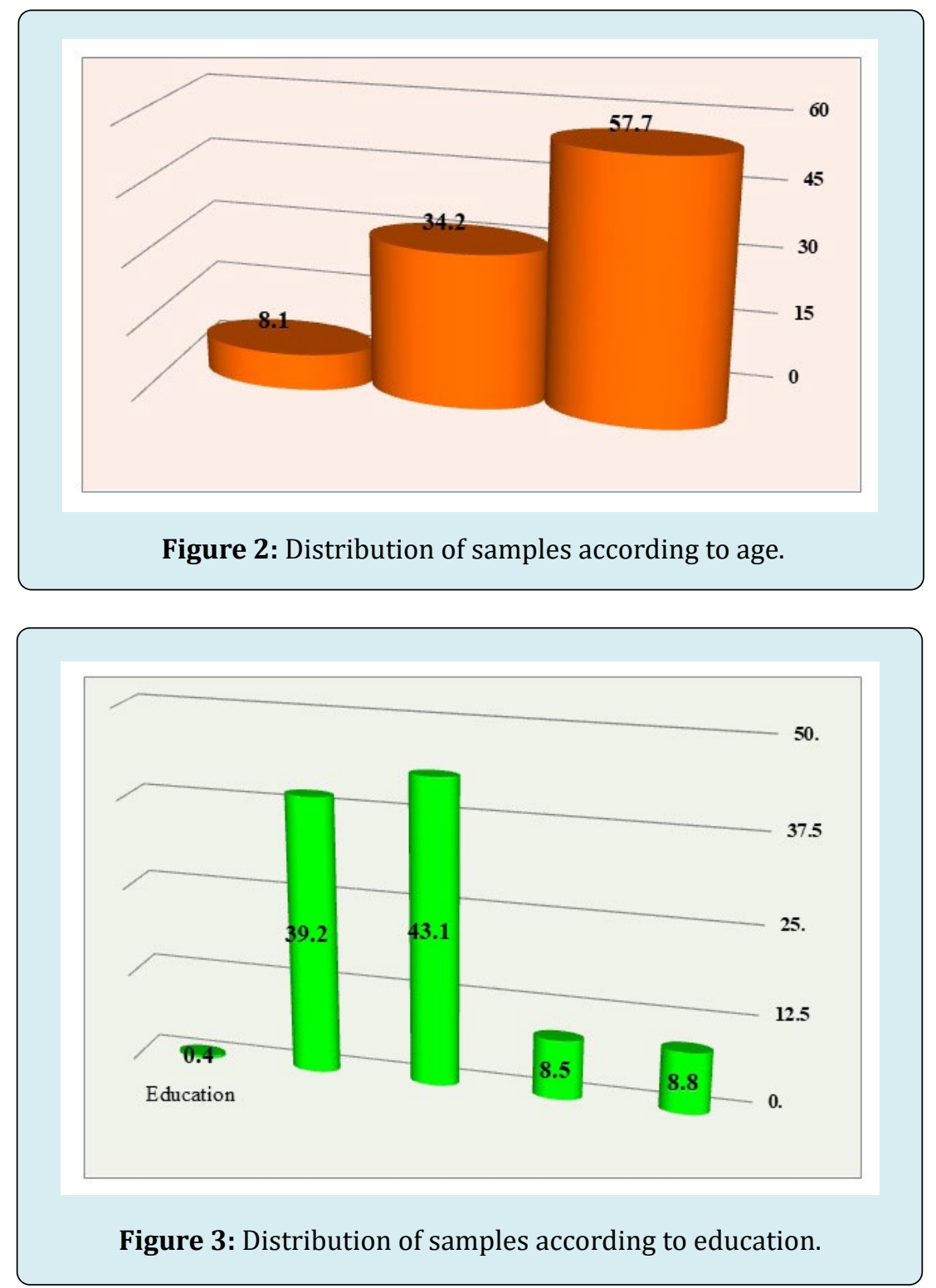

Kaur G, et al. Assessment of Awareness of Risks to Prevent Uterine Prolapse among Young Married Women in Selected Villages of District Sirmour, Himachal Pradesh. Nurs Health Care Int J 2020, 4(3): 


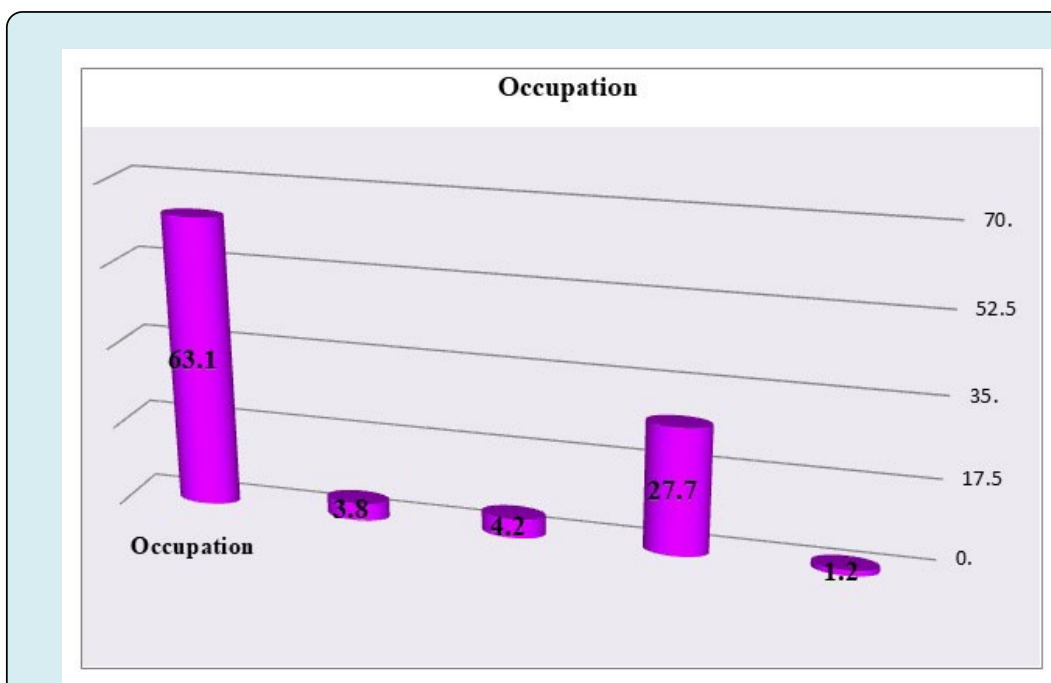

Figure 4: Distribution of samples according to occupation.

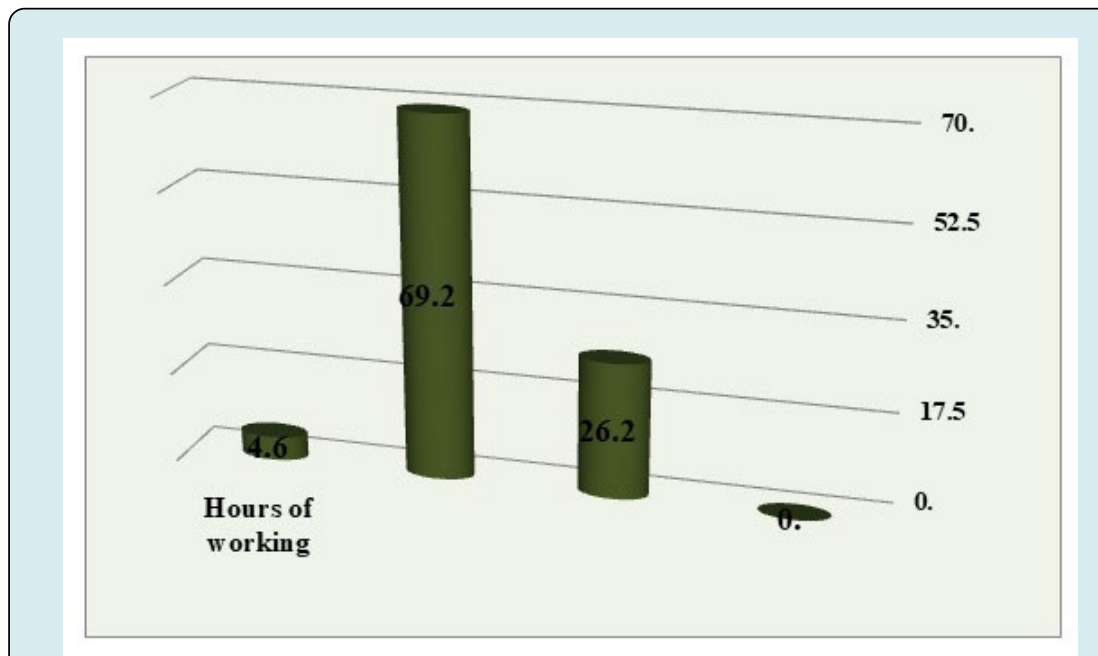

Figure 5: Distribution of samples according to hours of working.

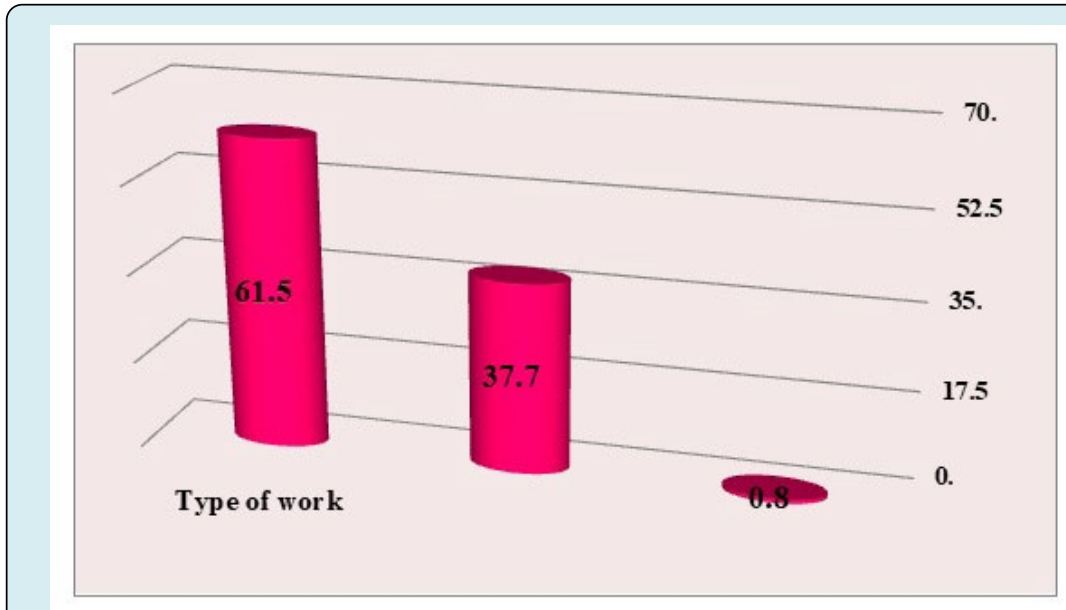

Figure 6: Distribution of samples according to type of work. 


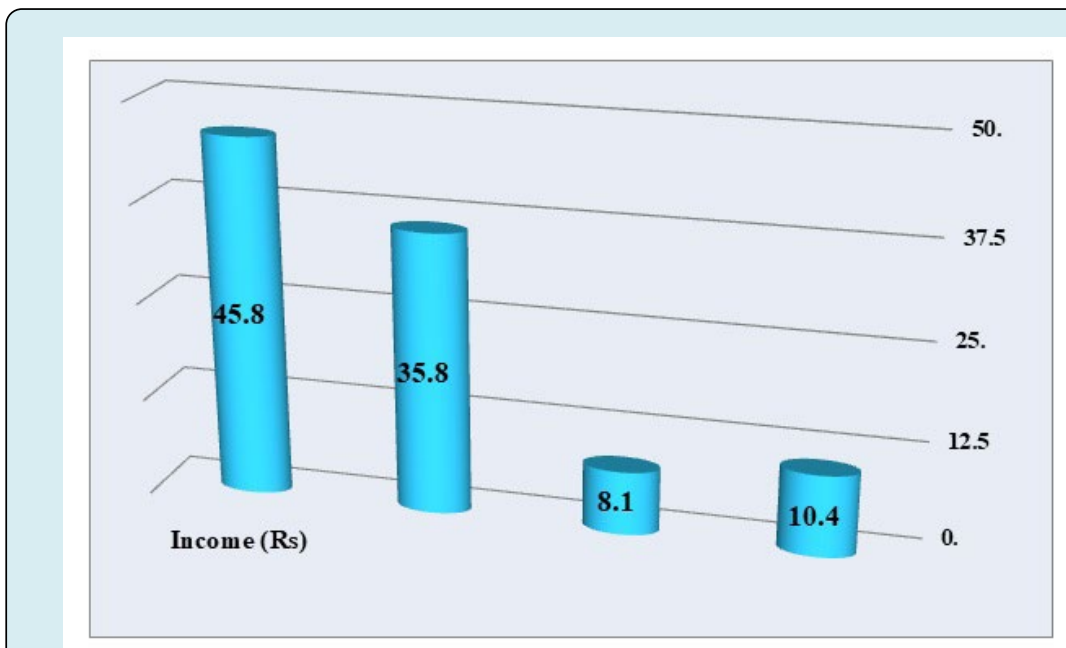

Figure 7: Distribution of samples according to income.

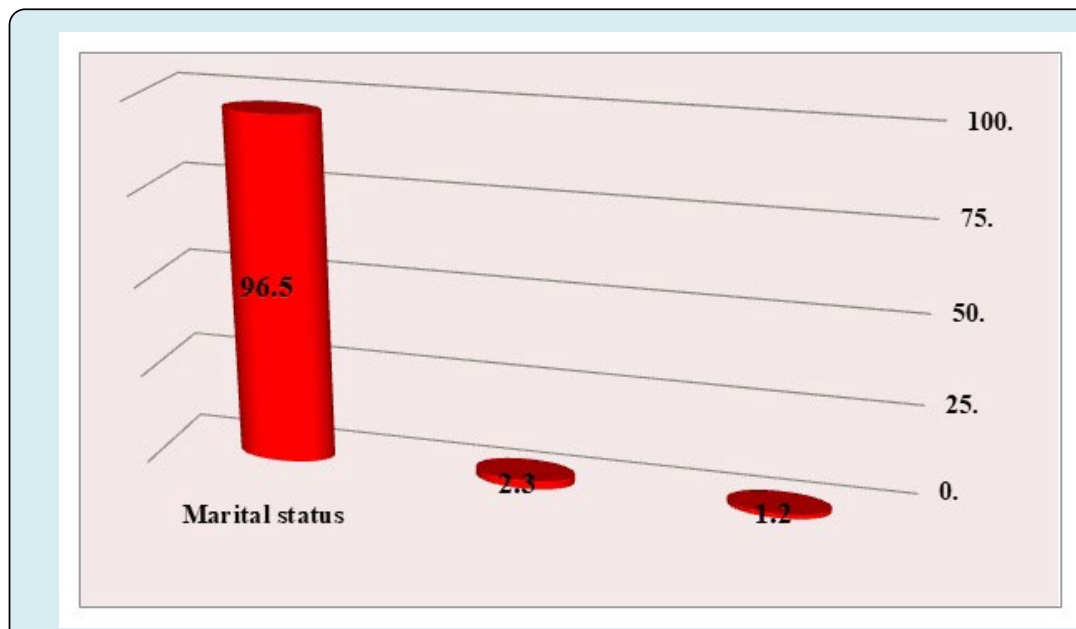

Figure 8: Distribution of samples according to marital status.

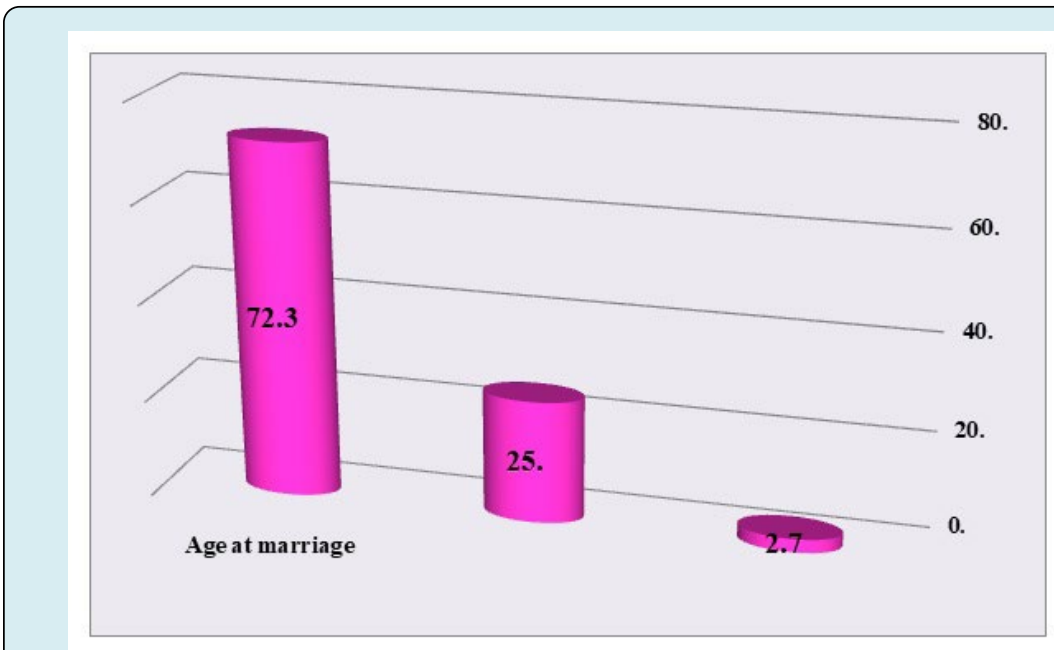

Figure 9: Distribution of samples according to age at marriage. 


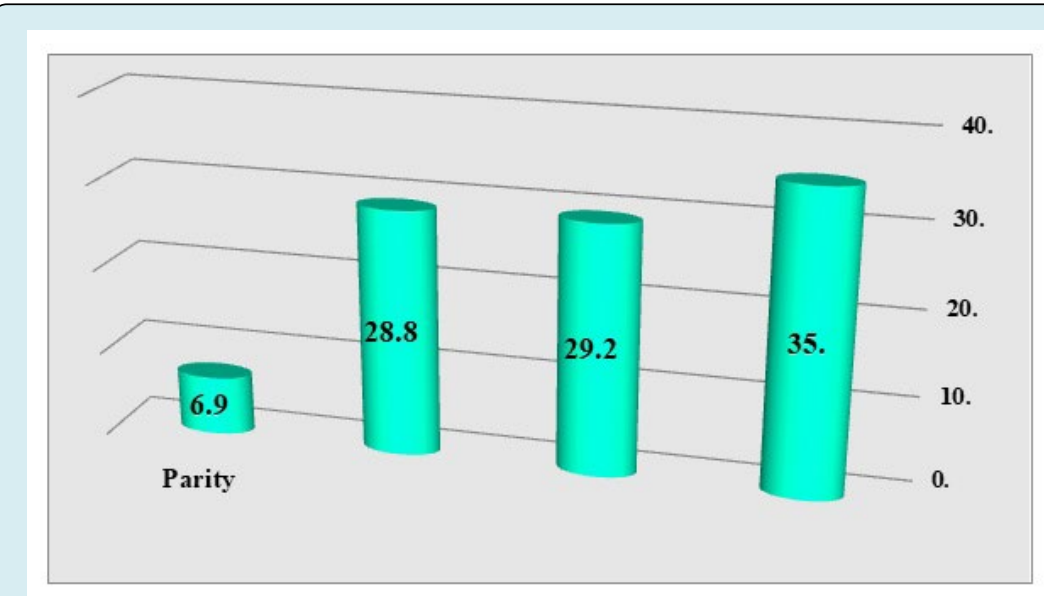

Figure 10: Distribution of samples according to parity.

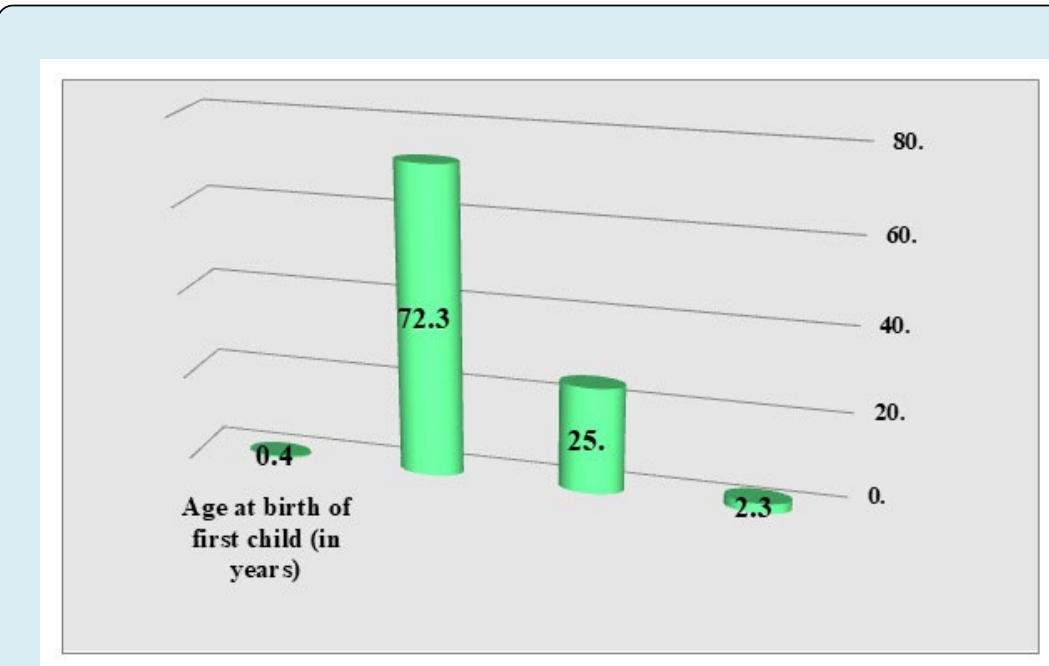

Figure 11: Distribution of samples according to age at birth of first child.

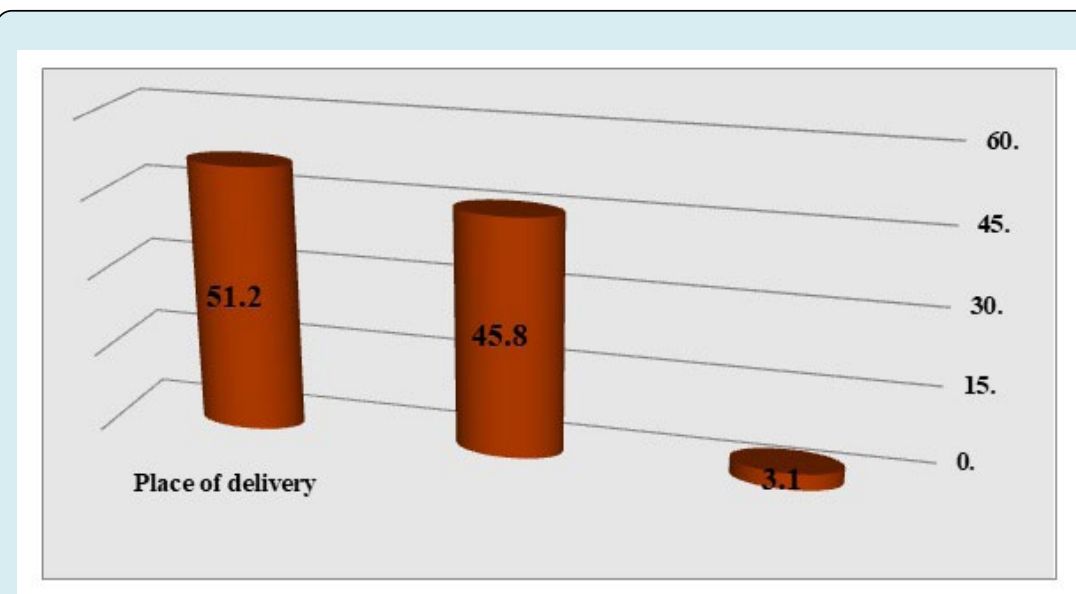

Figure 12: Distribution of samples according to place of delivery. 


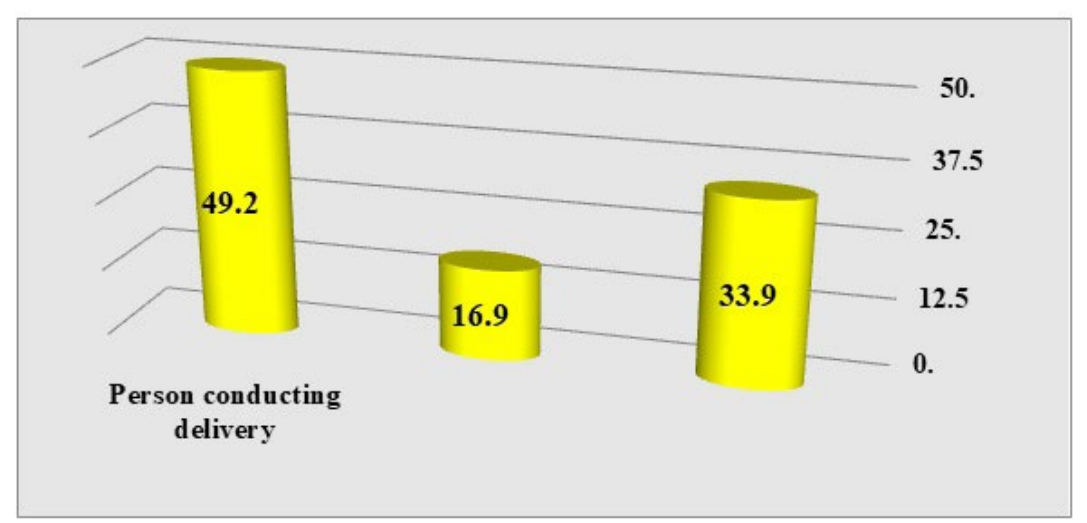

Figure 13: Distribution of samples according to person conducting delivery.

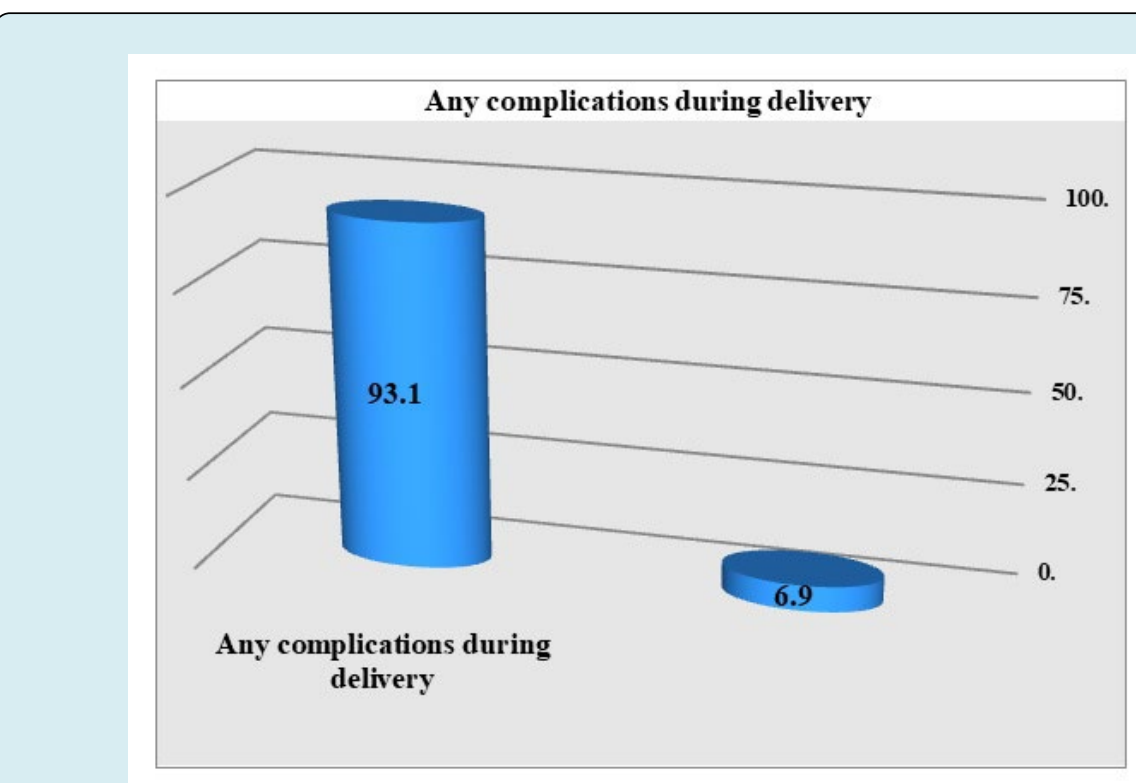

Figure 14: Distribution of samples according to any complications during delivery.

\section{Section B: Assess awareness of risk findings regarding uterine prolapse among young married women}

This section includes a structured interview schedule to assess awareness of risk regarding uterine prolapse.
The samples answered a total of 12 close ended questions. Each correct response was given one mark and 0 score for incorrect response with a maximum of 12 marks.

\begin{tabular}{|c|c|c|c|c|c|}
\hline \multirow{2}{*}{ Sr. No. } & Questions & \multicolumn{2}{|c|}{ Aware } & \multicolumn{2}{c|}{ Not aware } \\
\cline { 3 - 6 } & f & \% & f & \% \\
\hline 1 & How will you recognize uterine prolapse? (yes= something \\
coming out of vagina, No= others) & 90 & 34.6 & 170 & 65.4 \\
\hline 2 & $\begin{array}{c}\text { Do you think delivery by untrained birth attendants is a risk of } \\
\text { uterine prolapse? (Yes= Aware, No= Not aware) }\end{array}$ & 206 & 79.2 & 54 & 20.8 \\
\hline 3 & $\begin{array}{c}\text { Do you think heavy lifting is a risk of uterine prolapse? (Yes= } \\
\text { Aware, No= Not aware) }\end{array}$ & 243 & 93.5 & 17 & 6.5 \\
\hline
\end{tabular}




\begin{tabular}{|c|c|c|c|c|c|}
\hline 4 & $\begin{array}{c}\text { Do you think prolonged labor for 18 hours is a risk of uterine } \\
\text { prolapse? (Yes= Aware, No= Not aware) }\end{array}$ & 175 & 67.3 & 85 & 32.7 \\
\hline 5 & $\begin{array}{c}\text { Do you think doing heavy work during post natal period till 42 } \\
\text { days is a risk for uterine prolapse? (Yes= Aware, No= Not aware) }\end{array}$ & 221 & 85 & 39 & 15 \\
\hline 6 & $\begin{array}{c}\text { Do you think inadequate diet during pregnancy cause uterine } \\
\text { prolapse? (Yes= Aware, No= Not aware) }\end{array}$ & 111 & 42.7 & 149 & 57.3 \\
\hline 7 & $\begin{array}{c}\text { Do you think chronic cough for more than 1year is a risk for } \\
\text { uterine prolapse? (Yes= Aware, No= Not aware) }\end{array}$ & 135 & 51.9 & 125 & 48.1 \\
\hline 8 & $\begin{array}{c}\text { Do you think constipation is a risk factor for uterine prolapse? } \\
\text { (Yes= Aware, No= Not aware) }\end{array}$ & 155 & 59.6 & 105 & 40.4 \\
\hline 9 & $\begin{array}{c}\text { Does overweight is a risk for uterine prolapse? (Yes= Aware, No= } \\
\text { Not aware) }\end{array}$ & 99 & 38.1 & 161 & 61.9 \\
\hline 10 & $\begin{array}{c}\text { Do you think giving birth to more than 2 children is the major } \\
\text { risk for uterine prolapse? (Yes= Aware, No= Not aware) }\end{array}$ & 65 & 25 & 195 & 75 \\
\hline 11 & $\begin{array}{c}\text { Do you think giving birth to large baby is a risk for uterine } \\
\text { prolapse? (Yes= Aware, No= Not aware) }\end{array}$ & 69 & 26.5 & 191 & 73.5 \\
\hline 12 & $\begin{array}{c}\text { Do you think trauma/injury during child birth is a risk for } \\
\text { uterine prolapse? (Yes= Aware, No= Not aware) }\end{array}$ & 23 & 8.8 & 237 & 91.2 \\
\hline
\end{tabular}

Table 1: Frequency and percentage distribution of awareness of risk findings regarding uterine prolapse.

Table 1 reveals that about $90(34.6 \%)$ women were aware and 170(65.4\%) were not aware regarding recognizing uterine prolapse, delivery by untrained birth attendants is a risk of uterine prolapse was aware to about $206(79.2 \%)$ but $54(20.8 \%)$ were not aware, majority of women $243(93.5 \%)$ were aware that heavy lifting is a risk of uterine prolapse as compared to $17(6.5 \%)$ were not aware regarding it, about $175(67.3 \%)$ were aware and $85(32.7 \%)$ were not aware that prolonged labor for 18 hours is a risk of uterine prolapse, doing heavy work during post natal period till 42 days was aware to $221(85 \%)$ as $39(15 \%)$ were not aware regarding this as a risk factor, about 111(42.7\%) were aware and $149(57.3 \%)$ were not aware that inadequate diet during pregnancy cause uterine prolapse. About $135(51.9 \%)$ women were aware that constipation is a risk factor for uterine prolapse as $125(48.1 \%)$ were not aware. More than half of the women $161(61.9 \%)$ were not aware but $98(38.1 \%)$ were aware of that overweight is a risk for uterine prolapse. Around 65(25\%) were aware as 195(75\%) were not aware that giving birth to more than 2 children is a major risk for uterine prolapse, giving birth to large baby was aware to $69(26.5 \%)$ but $191(73.5 \%)$ were not aware is a risk factor. Majority of women 237(91.2\%) were not aware that trauma/injury during childbirth is a risk for uterine prolapse as $23(8.8 \%)$ were aware regarding it.

\begin{tabular}{|c|c|c|c|}
\hline Variable & Level & f & \% \\
\hline \multirow{3}{*}{ Awareness of risk regarding uterine prolapse } & High level & 35 & 14 \\
\cline { 2 - 4 } & Moderate level & 108 & 42 \\
\cline { 2 - 4 } & Low level & 117 & 45 \\
\hline
\end{tabular}

Table 2: Distribution of awareness of risk regarding uterine prolapse according to levels by Modified Bloom's cutt off point.

Modified Blooms cut off points were used to determine awareness level. A total of 12 yes/no questions were prepared by reviewing the different sources of literature (Table 2). A score of 1 was given for each correct response and 0 score for incorrect response. Based on the sum scores, level of awareness of risk was classified into Low level awareness $(<50 \%)$, Moderate level awareness (50-79\%) and High level awareness $(80-100 \%)$.
About (45\%) had low level $(<50 \%)$ of awareness, $41.5 \%$ of them had moderate level of awareness (50\%-79\%) and remaining $13.5 \%$ of them had high level of awareness (80$100 \%$ ) of risk regarding uterine prolapse. Therefore, nearly $86.5 \%$ of the women in this study had a low to moderate level of awareness about the awareness of risk regarding uterine prolapse (Figure 15). 


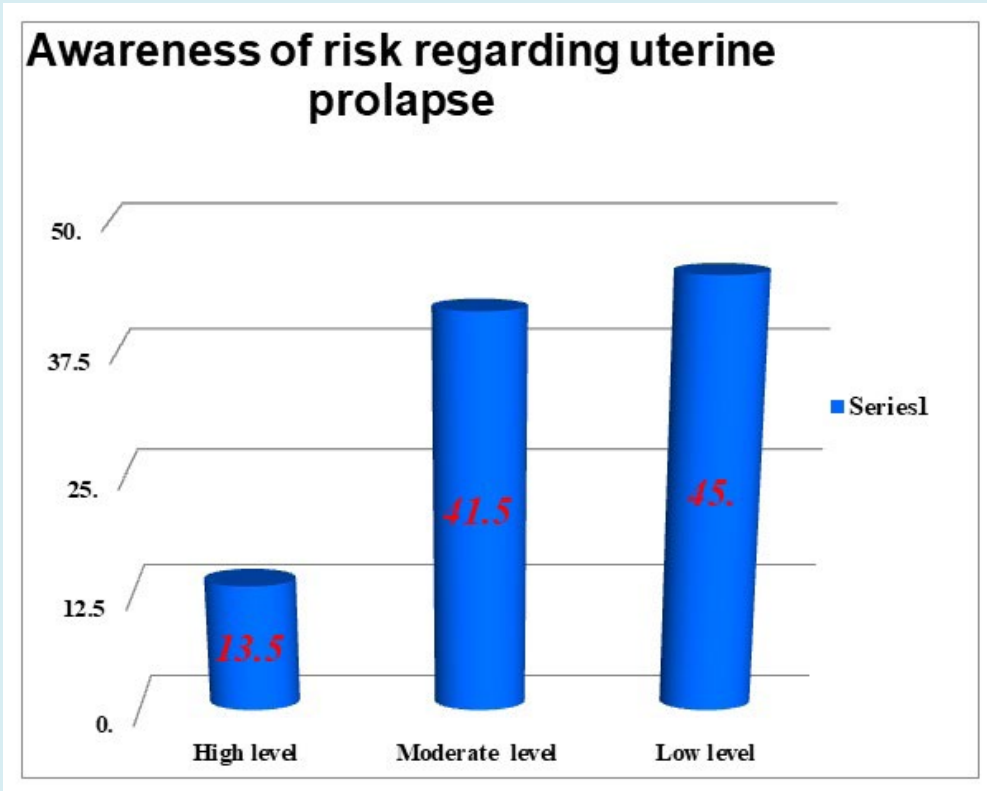

Figure 15: Distribution of samples according to awareness of risk regarding uterine prolapse.

Section C: Association between awareness of risk findings with selected demographic variables.

This section includes association between awareness of risk findings with selected demographic variables as age, education, occupation, hours of working, type of work, income, marital status, parity, age at marriage, age at birth of first child, place of delivery, person conducting delivery and any complications during delivery which is calculated by chi square.

\begin{tabular}{|c|c|c|c|c|}
\hline \multirow{2}{*}{ Variables } & \multicolumn{3}{|c|}{ Awareness of risk } \\
\cline { 2 - 5 } & $X^{2}$ & df & t value & Sig (0.05) \\
\hline Age & 4.97 & 4 & 9.49 & 0.29 \\
\hline Education & 17.191 & 8 & 15.51 & 0.028 \\
\hline Occupation & 21.233 & 8 & 15.51 & 0.007 \\
\hline Hours of working & 19.592 & 4 & 9.49 & 0.001 \\
\hline Type of work & 15.574 & 4 & 9.49 & 0.004 \\
\hline Income & 11.578 & 6 & 12.59 & 0.072 \\
\hline Marital status & 2.954 & 4 & 9.49 & 0.566 \\
\hline Parity & 12.231 & 6 & 12.59 & 0.057 \\
\hline Age at marriage & 18.266 & 4 & 9.49 & 0.001 \\
\hline Age at birth of first child & 23.143 & 6 & 12.59 & 0.001 \\
\hline Place of delivery & 31.067 & 6 & 12.59 & 0 \\
\hline Person conducting delivery & 18.394 & 6 & 12.59 & 0.002 \\
\hline
\end{tabular}

Table 3: Association between awareness of risk findings with selected demographic variables.

Table 3 depicts that there was a significant relationship between education, occupation, hours of working, type of work, age at marriage, age at birth of first child, place of delivery, person conducting delivery with awareness of risk 
regarding uterine prolapse.

It was also observed that there was no significant relationship between age, income, marital status, parity, any complications during delivery with awareness of risk regarding uterine prolapse.

\section{Discussion}

The discussion deals with the findings of the study. The findings of the each objective are as follows:

Assess awareness of risk regarding uterine prolapse. In this study it was found that majority $90(34.6 \%)$ women were aware regarding recognizing uterine prolapse, delivery by untrained birth attendants is a risk of uterine prolapse was aware to about 206(79.2\%), a large number of women $243(93.5 \%)$ were aware that heavy lifting is a risk of uterine prolapse as, about $175(67.3 \%)$ were aware that prolonged labor for 18 hours is a risk of uterine prolapse, doing heavy work during post natal period till 42 days was aware to $221(85 \%)$ regarding this as a risk factor, about $111(42.7 \%)$ were aware that inadequate diet during pregnancy cause uterine prolapse. About half of the women 135(51.9\%) were aware that constipation is a risk factor for uterine prolapse, only $98(38.1 \%)$ women were aware of that overweight is a risk for uterine prolapse, around 65(25\%) were aware that giving birth to more than 2 children is a major risk for uterine prolapse, giving birth to large baby was aware to $69(26.5 \%)$ is a risk factor, trauma/injury during childbirth is a risk for uterine prolapse as $23(8.8 \%)$ women were aware regarding it.

In a study conducted by Baruwal [8-10] found that the majority of respondents had knowledge that delivery by untrained birth attendants $(80.5 \%)$ and carrying heavy load during pregnancy $(80.5 \%)$ cause uterine prolapse. Nearly $90 \%$ of the respondents answered that doing heavy work during pre and post natal period cause uterine prolapse. More than $50 \%$ of women disagreed with the statement that having many children reduces the risk of uterine prolapse. About (32\%) women think that having not enough food during pregnancy cause uterine prolapse and $52.3 \%$ think that undergoing labor for long period causes uterine prolapse.

In the present study chi square test was used to calculate the association between awareness of risk with selected variables. Results of present study reveals there is significant association between selected variables as education $(p=0.028)$, occupation (0.007), hours of working ( $p=0.001)$, type of work $(p=0.004)$ age at birth of first child $(p=0.001)$, place of delivery $(\mathrm{p}=0.000)$ and person conducting delivery $(\mathrm{p}=0.002))$ with awareness of risk regarding uterine prolapse at $\mathrm{p}<0.005$. Hence research hypothesis for this study was accepted.

This study is supported by the results of the study conducted by Baruwal [8] found out the association with chisquare and it reveals that the relationship between education and status of prolapse was not significant $(p=0.65)$, even there is no significant difference $(p=.799)$ between occupation and status of uterine prolapse. There is no significant difference between place of delivery $(\mathrm{p}=.183)$, delivery practices $(\mathrm{p}=.114)$ and status of uterine prolapse.

\section{Conclusion}

Uterine prolapse affects women both in the child bearing age and post menopausal period. As pregnancy and childbirth are such physiological phenomenon which cannot be prevented but we can prevent the repeated pregnancies at short intervals and deliveries by untrained dais at home. Thus multi-parity, prolonged labour, deliveries by untrained dais, less spacing between children are significant determinants.

\section{References}

1. Sharmilla R (2013) Pelvic Organ Prolapse. Nightingale Nursing Times 9(3): 52-54.

2. Carlson K J, Eisenstat S A, Ziporyn T (1996) The Harvard Guide to Women's Health. In: Prolapsed Uterus. Cambridge, Massachusetts, London and England: Harvard University Press Publishing, pp: 516-517.

3. Lowdermilk DL, Perry, Bobak (1997) Maternity and Women's Health Care. In: Ledbetter MS, (Eds.), Structural Disorders and Neoplasms of the Reproductive System. US: Mosby Publishings, pp: 1262-1295.

4. Ojiyi EC, Dike EI, Anolue FC, Okeudo C, Nzewuihe ACE, et al. (2013) Uterovaginal prolapse at a University Teaching Hospital in South-East Nigeria. Orient Journal of Medicine 25 (3-4): 107-112.

5. Hoffmann BL, Schorge JO, Schaffer JI, Halvorson LM, Bradshaw KD, et al. (2012) Williams Gynecology. In: Fried A, et al. (Eds.), Pelvic Organ Prolapse, Mc Graw-Hill Publishing, China, pp: 633-656.

6. Scherf C, Morison L, FianderA, Ekpo G, Walraven G (2002) Epidemiology of pelvic organ prolapses in rural Gambia, West Africa. BJOG 109(4): 431-436.

7. Bijalwan RP, Bhagavatula M, Semwal VD, Rawat P, Anand V (2015) Morbidity of Uterine Prolapsed among the Women in the Chakrata Block of Dehradun District. Indian Journal of Community Health 27(1):103-109.

8. Baruwal A, Somronthong R, Pradhan S(2011) Knowledge, 
Attitude and Preventive Measures Amongst Married Women of Reproductive Age towards Uterine Prolapse in the Eight Villages of Surkhet District of Nepal. Journal of Health Research 25(3): 129-133.

9. Patil P, Patil A (2013) Evaluations of pelvic organ prolapse in Indian females. Journal of Evolution of Medical and
Dental Sciences 2(40): 7612-7620.

10. Palm S (2013) The Value of Sustainable Protocol to Address Uterine Prolapse in Nepal: Health Camp, Awareness and Employment Strategy. Association for Pelvic Organ Prolapse Support pp: 1-15. 